\title{
Hedonic and Eudaimonic Well-Being in Late Adulthood: Lessons From Sardinia's Blue Zone
}

\author{
Maria Chiara Fastame ${ }^{1}$ (D) $\cdot$ Marilena Ruiu ${ }^{1} \cdot$ Ilaria Mulas $^{1}$
}

Accepted: 2 June 2021 / Published online: 6 July 2021

(c) The Author(s) 2021

\begin{abstract}
This study was conducted to investigate whether socio-cultural context (i.e., urban versus rural), perceived physical health, marital status, and satisfaction with family and non-family ties predicted hedonic and eudaimonic well-being in late adulthood and to examine the impact of the socio-cultural context on well-being, physical health and satisfaction with family and non-family ties by controlling age.One hundred and one community-dwelling participants aged between 68 and 94 were enrolled in the Sardinian Blue Zone-an area of exceptional longevity located in Sardinia, an Italian island in the Mediterranean Seaand in the city of Cagliari-the regional capital. All participants completed a battery of tools assessing global cognitive efficiency, hedonic (i.e., SPANE and Satisfaction with Life Scales) and eudaimonic (i.e., Flourishing Scale) well-being, perceived physical health, and satisfaction with family and non-family ties. Hedonic and eudaimonic well-being were associated with several variables: marital status, socio-cultural context, and perceived physical health predicted $24 \%$ of the variance in the SPANE condition, $52 \%$ of the variance in the Satisfaction with Life condition was predicted by the socio-cultural context and satisfaction with family ties, whereas $39 \%$ of the Flourishing index was predicted by the socio-cultural context and physical health. Finally, the participants in the Sardinian Blue Zone reported better mental well-being and satisfaction with family and non-family ties than older people living in Cagliari. In conclusion, a socio-cultural context in which positive relationships in late adulthood are strengthened contributes to the promotion of mental health in late adulthood.
\end{abstract}

Keywords Well-being $\cdot$ Aging $\cdot$ Blue Zone $\cdot$ Eudaimonic $\cdot$ Life satisfaction

\section{Introduction}

For decades, the study of well-being has been oriented to the definition of its hedonic and eudaimonic features. These are fundamental facets of life quality in adult span lacking consistent assessment. In brief, hedonia is a way of feeling well and happy, avoiding

Maria Chiara Fastame

chiara.fastame@unica.it

1 Department of Pedagogy, Psychology, Philosophy, University of Cagliari, Via Is Mirrionis 1, 09123 Cagliari, Italy 
distress and unpleasant emotional status, and promoting pleasure and satisfaction with life. In contrast, eudaimonia refers to a way of behaving designed to the full development of our potentials, i.e. it is a motivation for human action to the promotion of a "flourishing life". The latter refers to a life full of purpose, meaning, and values, which are considered the cause of real happiness (VandenBos \& APA, 2015). Thus, if on the one hand hedonic well-being is aimed at maximizing pleasant feelings and minimizing painful ones, on the other hand, eudaimonia goes beyond pleasure-driven satisfaction and happiness, since it is oriented toward personal growth and the realization of an individual's full potentials.

As pointed out by Huta and Ryan (2010), eudaimonia and hedonia are independent, not mutually exclusive, and partly overlapping variables. In this perspective, the greatest wellbeing is the combination of very high hedonic and eudaimonic dimensions.

A tradition of research suggests that psychological aspects of well-being are strictly related to the promotion of positive aging. As pointed out in the gerontology literature (e.g., Carver \& Buchanan, 2016; Cosco et al., 2014), although there is no consensus about its definition, positive aging and some concurrent semantically similar terms, such as active, healthy, optimal and successful aging, are used to refer to a multidimensional construct encompassing distinct dimensions of well-being (e.g., life satisfaction, flourishing), physical and cognitive efficiency and social engagement in late adulthood (Fernandez-Ballesteros, 2011; see also Bowling, 1993). Therefore, in this article they will be considered synonyms and they will be interchanged.

Studies conducted in areas of extraordinary longevity can be very informative about the individuations of the factors promoting successful aging in terms of superior functional status, increased life quality and greater mental health. Relative to this issue, relevant findings indicate the presence of five rural areas characterized by the extraordinary longevity of the inhabitants, the so-called Blue Zones, which are located in Japan (i.e., Okinawa), Costa Rica (i.e., Nicoya), USA (i.e., Noma Linda), Greece (i.e., Ikaria) and Italy (i.e., Sardinia) (Poulain et al., 2013). Regarding the Italian Blue Zone, which is the focus of this article, it is limited to the central-eastern mountainous area of Sardinia, where historically the inhabitants are mainly shepherds and where a similar prevalence of female and male centenarians has been found (Pes et al., 2015). A variety of evidence suggests that different factors contribute to the successful aging of the older individuals living in the Sardinian Blue Zone; specifically, genetic, physiological metabolic and environmental factors, dietary habits (i.e., moderate consumption of meat and dairy products and a high intake of plant-based products), lifestyle, and some positive psychological characteristics have been pointed out (e.g., Fastame, Hitchcott and Penna, 2018; Manca et al., 2021; Nieddu et al., 2020; Pes et al., 2013). In terms of the psychological markers of successful aging, a research trend has highlighted that cognitively healthy (i.e., assessed through the Mini-Mental State Examination and a battery of working memory tasks) community-dwelling older people of the Sardinian Blue Zone reported fewer depressive signs (e.g., Fastame, Penna and Rossetti, 2014), and better psychological well-being (e.g., Fastame \& Penna, 2014) than peers presenting the same cognitive and socio-demographic characteristics (e.g., global cognitive efficiency, age, gender, education level) and a similar very simple lifestyle, but who were recruited in a rural area of northern Italy. Interestingly, compared to the national cut-off scores, older people of the Sardinian Blue Zone self-reported higher levels of psychological well-being and lower levels of depression, which, in turn, were associated with more preserved active working memory functions and metacognitive resources (Fastame, Penna, Rossetti, and Agus, 2014; for a review, see Hichcott, Fastame and Penna, 2018). More recently, in a follow-up study, Fastame, Mulas and Pau (2020) found that, compared to the national norms, a group of older individuals enrolled in the Sardinian Blue Zone 
reported better psychological well-being and lower depressive signs even two years after the first assessment. Consistently, Fastame, Penna and Hitchcott (2020) found this advantage in terms of higher well-being and lower depressive signs in a sample of communitydwelling longevous individuals of the Sardinian Blue Zone and centenarians, documenting that mental health is preserved even in the last decades of life. Thus, as suggested elsewhere (e.g., Diener et al., 2018), Fastame, Penna, \& Hitchcott (2020) speculated that, in a socio-cultural context where the older adults are treated with respect and are considered a resource for their community (e.g., being useful for the others), this attitude positively impacts their self-reported mental health and it contributes significantly to quality of life. Consistently, a further pattern of findings highlighted that, in contexts characterized by the prevalence of collectivistic values such as the Chinese one (e.g., Chyi \& Mao, 2012; Williams et al., 2017), in which interpersonal dependency and positive relationships are strengthened, marital status, satisfaction with family and non-family ties impact different aspect of self-reported mental health, such as general well-being. In line with this, an investigation conducted among family members (i.e., grandparents, children and grandchildren) in the Sardinian Blue Zone (Hitchcott et al., 2017) pointed out that self-reported satisfaction with family relationships and satisfaction with friendships predicted well-being assessed through the Warwick-Edinburgh Mental Well-Being Scale (i.e., Tennant et al., 2007; Italian adaptation, Gremigni \& Stewart-Brown, 2011). This is a self-report inventory providing a total measure of subjective hedonic and eudaimonic well-being. In a further study, it has been observed that, in older people of the Sardinian Blue Zone, psychological well-being (i.e., assessed through the Warwick-Edinburgh Mental Well-Being Scale) was mainly predicted by satisfaction with family and non-family members, marital status and optimal regulation (i.e., a dispositional resilience trait implicated in the management of negative emotions, Fastame, Hitchcott, Mulas, Ruiu, and Penna, 2018).

However, it must be noticed that, so far, no studies have investigated whether the higher well-being pattern highlighted in the Sardinians of the Blue Zone can be extended to older adults residing in further Sardinian urban areas. Indeed, thus far, to our knowledge, only one study has examined the depressive patterns of cognitively healthy Sardinian people, pointing out that older participants in the Blue Zone reported significantly fewer depressive signs than older inhabitants enrolled in the town of Sassari (Fastame, Penna and Hitchcott, 2015).

Moreover, to our knowledge, no studies have investigated different dimensions of eudaimonic and hedonic well-being in older people living in zones of exceptional longevity by means of internationally well-known psychological tools (see below) developed for the assessment of specific facets of eudaimonic or hedonic well-being. Indeed, so far, apart from the administration of a well-known inventory self-rating depressive symptoms (i.e., Center for Epidemiologic Studies-Depression scale, CES-D by Radloff, 1977), the studies conducted with older people of the Sardinian Blue Zone (e.g., Fastame, Penna and Rossetti, 2014; Fastame, Penna and Hitchcott, 2020) were mainly based on the administration of tools (e.g., Warwick-Edinburgh Mental Well-Being Scale by Tennant et al., 2007) that did not provide distinct scores relative to the eudaimonic and hedonic dimensions of wellbeing. Finally, to the best of our knowledge, evidence is lacking in terms of the possible relationship between external factors (e.g., marital status, social capital) and eudaimonic and hedonic well-being measures in people living in areas of extreme longevity (i.e., Blue zones). 


\section{The study}

This study aimed to examine: (1) the nature of the associations among hedonic and eudaimonic well-being, perceived physical health, and satisfaction with family and nonfamily relationships; (2) whether some contextual (i.e., urban versus rural) and non-contextual (i.e., physical health, marital status, and satisfaction with family and non-family relationships) factors predict different measures of hedonic and eudaimonic well-being in cognitively healthy old participants; (3) the impact of socio-cultural context on mental health (i.e., hedonic and eudaimonic well-being), physical health, and satisfaction with family and non-family relationships in late adulthood, controlling for the effect of age.

For the aims of this investigation, hedonic well-being was assessed through the Scale of Positive and Negative Experience (SPANE, Diener et al., 2009; Italian version, Giuntoli et al., 2017) and the Satisfaction with Life Scale (SWLS, Diener et al., 1985; Pavot \& Diener, 1993; Italian version, Di Fabio \& Gori, 2020). Eudaimonic well-being was assessed through the Flourishing Scale (Diener et al., 2009, Italian version, Giuntoli et al., 2017). Concerning this, there is evidence that, in middle and late adulthood, the prevalence of positive feelings assessed through the SPANE scale are associated with greater satisfaction with social ties and greater satisfaction with personal achievements in life (Rojo-Perez et al., 2012). Similarly, the presence of supportive and rewarding relationships and feelings of autonomy, competence (e.g., support others), and being respected boost flourishing in late adulthood (Killen \& Macaskill, 2015). Moreover, there is evidence that social support is strongly associated with life satisfaction (i.e., assessed through the SWLS) in older people, especially in those with chronic diseases (Lee et al., 2020).

In the current study, to investigate the impact of the socio-cultural context on selfreported mental health indexes, participants were recruited in one village of the Sardinian Blue Zone, namely Dorgali (i.e. a rural village with \pm 8500 inhabitants located on the eastern central coast of Sardinia) and in the city of Cagliari (i.e. a large administrative center in Sardinia with $\pm 154,000$ inhabitants, located on the southern coast of the island). Part of the sample was enrolled in Dorgali because, unlike other mountainous villages of the Sardinian Blue Zone, Dorgali shares some environmental characteristics (e.g., reduced slope of the territory approaching the coastal area) with Cagliari that could produce similar physical health outcomes (Pes et al., 2013).

To our knowledge, this is the first investigation in which the above-mentioned hedonic and eudaimonic well-being tools were administered to explore the impact of the socio-cultural context (i.e. Blue Zone versus Sardinian urban area) on mental health measures. This seems very crucial, since this study can provide meaningful information to expand our knowledge about the wellness facets and about the factors contributing to the promotion of the psychological aspects shaping positive aging.

Relating to the first goal of the study, significant associations were expected between each psychological well-being measure, and perceived physical health and satisfaction with family relationships, respectively (Fastame, 2020). In terms of the second goal of the study, it was hypothesized that:

(1) satisfaction with family and non-family relationships was expected to predict eudaimonic and hedonic well-being indexes (Diener et al., 2018; Fastame, Hitchcott, Mulas et al., 2018; Hitchcott et al., 2017; Rojo-Perez et al., 2012). 
(2) perceived physical health was expected to predict well-being measures (Fastame et al., 2017).

(3) socio-cultural context was expected to be a significant predictor of each psychological well-being measure (Fastame, Hitchcott, and Penna 2015).

(4) marital status was expected to be a significant predictor of well-being (e.g., Fastame, Hitchcott, Mulas, et al., 2018).

Furthermore, related to the third aim, no significant differences were expected in terms of perceived physical health of the older participants recruited in the Sardinian urban and Blue Zone areas, since the environmental characteristics of the territories are similar (Pes et al., 2013). Moreover, following Fastame, Hitchcott, and Penna (2015), older people of the Blue Zone were expected to report better psychological well-being than peers living in the urban area. Finally, due to a lack of previous evidence, no further a priori predictions were proposed.

\section{Method}

\subsection{Participants}

A sample of 106 community-based 68-94-year-old adults (mean age $=78.10$ years, $\mathrm{SD}=6.6$ ) living in the urban area of Cagliari and at Dorgali (i.e., a rural village of the Sardinian Blue Zone) participated in this study. All the respondents were recruited through personal contacts, word of mouth and via the collaboration of community centers for older people (e.g., University of the Third Age) contacted by the second and third authors.

In order to take part in the study, participants had to satisfy the following criteria: (1) to be born and resident in Cagliari or in the Sardinian Blue Zone, respectively; (2) to be a descendent of families living in those areas for at least two previous generations; (3) to be community-dwelling (i.e., non-institutionalized); (4) to be cognitively intact, that is, obtaining a score $\geq 24 / 30$ using the Mini-Mental State Examination test (MMSE, Folstein et al., 1975).

Five participants had MMSE scores adjusted for age and education (Magni et al., 1996) below 24, therefore they were excluded from further testing for suspected mild cognitive decline. Accordingly, the analyses reported below where conducted on a final sample composed of 101 respondents, 53 participants $($ males $=22)$ from the city of Cagliari and 48 (males $=25$ ) from the Sardinian Blue Zone (i.e., Dorgali).

Following previous studies (e.g., Fastame, Hitchcott, and Penna, 2015; Fastame, Hitchcott and Penna, 2018), formal education attainment was dichotomized as low (i.e., $\leq 8$ years) and high (i.e., $>8$ years).

Education $\left(\chi^{2}=0.01, \mathrm{df}=1, p=0.92\right)$ was counterbalanced across the participants, whereas gender $\left(\chi^{2}=1.13, \mathrm{df}=1, p=0.29\right)$ and marital status (i.e., single/widowed vs. married) $\left(\chi^{2}=0.70, \mathrm{df}=1, p=0.40\right)$, were counterbalanced across the residential areas (i.e., Cagliari versus Dorgali). Table 1 illustrates the characteristics of the participants.

\subsection{Materials}

Participants were asked to complete the following battery of tools: 
Table 1 Socio-demographic characteristics of the participants of the study enrolled at Cagliari and Dorgali, respectively

\begin{tabular}{lll}
\hline Variable & Cagliari & Dorgali \\
\hline $\mathrm{n}$ & 53 & 48 \\
Gender & 22 & 25 \\
Males & 31 & 23 \\
Females & & \\
Marital status & 32 & 25 \\
Married & 21 & 23 \\
Single & & \\
Education & 20 & 30 \\
Low (0-8 years) & 33 & 18 \\
High (>8 years) & &
\end{tabular}

A preliminary structured interview was administered to collect information about sociodemographic (e.g., gender, age, marital status, education) and lifestyle (e.g., smoking, time spent for gardening or outdoor leisure activities) information of the respondents.

The MMSE (Folstein et al., 1975) was administered to test the general cognitive efficiency. This screening test assesses different cognitive functions such as attention, short and long-term memory. Scores were adjusted for age and years of education (Magni et al., 1996). The maximum score was 30 and a score $<24$ was used to exclude participants with suspected cognitive impairment.

The Flourishing Scale (Diener et al., 2009; Italian validation by Giuntoli et al., 2017) was used as a measure of eudaimonic well-being. Specifically, this tool is an 8 items selfreport questionnaire designed to rate important eudaimonic well-being facets, such as social relationships, having a purposeful and meaningful life and being engaged with an active life. For each item, the respondent assesses his/her degree of agreement on a Likert scale ranging from 1 (Complete agreement) to 7 (Complete disagreement). Thus, the total score ranges from 8 (strong disagreement with all items) to 56 (strong agreement with all items). In young adults, a score $\leq 32$ indicates a very low level of flourishing, whereas a score $\geq 54$ represents very high flourishing. So far, no norms are available to detect low flourishing in older people (see Diener et al., 2010). Following Nunnally and Bernstein (1994), as reported by Giuntoli et al. (2017), the Italian version of this scale presents good internal consistency $(\alpha=0.88)$.

The Scale of Positive and Negative Experience (SPANE, Diener et al., 2009; Italian version, Giuntoli et al., 2017) was used to assess hedonic well-being. This tool is composed of 6 items relative to positive experiences and 6 items concerning negative feelings. Each participant was asked to self-rate the occurrence of each described affective experience during the past 4 weeks on a Likert scale ranging from 1 (i.e., very rarely or never) to 5 (i.e., very often or always). The overall balance score (i.e., SPANE-B) was computed by subtracting the total score of the negative subscale (i.e., ranging from 6 to 30) from the total score relative to the positive items (i.e., ranging from 6 to 30). Therefore, the overall score could vary from -24 (rarely or never experiences of positive feelings) to 24 (rarely or never experiences of negative feelings). The reliability of the Italian version of this tool is pretty good and is expressed by Cronbach's $\alpha$ of 0.91 for the positive subscale and $\alpha=0.86$ for the negative one (Giuntoli et al., 2017).

The Satisfaction with Life Scale (SWLS; Diener et al., 1985; Pavot \& Diener, 1993; Italian version, Di Fabio \& Gori, 2020) is a 5-item-questionnaire assessing a further aspect of 
hedonic well-being, that is, global life satisfaction. Each participant was asked to express his/her level of agreement/disagreement about some subjective well-being situations on a Likert-type scale ranging from 1 (complete disagreement) to 7 (complete agreement). The total score ranges from 5 (very low life satisfaction) to 35 (maximum life satisfaction). A score $>29$ indicates that the level of satisfaction is very high, whereas a score included between 5 and 9 indicates extreme dissatisfaction. As reported by Di Fabio and Gori (2020), the Italian version of SWLS is pretty good $(\alpha=0.88)$.

The Perceived Physical Health measure (Fastame et al., 2017) includes 1 item assessing how the person rates his/her physical health on a Likert scale from 0 (worst health) to 10 (excellent health).

The Self-assessed personal satisfaction with family relationships index (Hitchcott et al., 2017) encompasses two items assessing the level of satisfaction of the respondent about his/her family ties during the past week on a 11-point Likert scale where 0 indicated the lack of satisfaction whereas 10 reflected the greatest level of satisfaction. The mean score between the answers was computed.

The self-assessed personal satisfaction with non-family relationships index (Hitchcott et al., 2017) was designed to evaluate the level of satisfaction of the participant about his/ her relationships with people not belonging to his/her family (e.g., friends, neighbors) during the past week. This measure is defined by two items and the scoring procedure is identical to that of the personal satisfaction with family relationships index.

\subsection{Procedure}

After that written informed consent was provided, each participant was individually tested in a quiet room of his/her own home. Initially, the MMSE was presented to test the general cognitive efficiency of each respondent, if signs of cognitive impairment were not detected, the socio-demographic interview was administered. Thereafter, the presentation order of the remaining measures was counterbalanced across the participants according to the Latin Square procedure. To reduce the fatigue effect, the examiner read aloud each statement of the questionnaires and recorded the responses given by the participant. Each experimental session lasted approximately $70 \mathrm{~min}$.

\section{Results}

First, Pearson's product-moment correlations were computed to check for multicollinearity and to explore the degree of association among Flourishing, Satisfaction with Life, Scale of Positive and Negative Experience, Perceived Physical Health, Satisfaction with family members and friends scores. Table 2 illustrates the findings of the correlational analyses.

In line with Pallant (2016), the above-mentioned measures were not highly correlated (i.e., $r \geq 0$.9), therefore, multicollinearity was excluded. Moreover, following Cohen (1988), small significant associations were found between perceived physical health and each wellbeing measure, whereas medium or large correlations were found among psychological well-being and satisfaction with family and non-family members scores.

Then, based on the results of the correlational analyses, three hierarchical linear regression analyses were conducted to examine whether some contextual (i.e., living in the urban area versus living in the Sardinian Blue Zone) and non-contextual (i.e., marital status, physical health, satisfaction with family and non-family relationships) factors could predict SPANE-B, 
Table 2 Zero-order correlations among the Flourishing Scale (i.e., Flourishing), balance score of the Scale of Positive and Negative Experience (i.e., SPANE-B), Satisfaction with Life Scale (i.e., SWLS), Perceived Physical Health (i.e., PHYS), Satisfaction with family members (i.e., Family) and Satisfaction with nonfamily members (i.e., Friends) scores, respectively

\begin{tabular}{lllllll}
\hline & Flourishing & SPANE-B & SWLS & PHYS & Family & Friends \\
\hline Flourishing & - & & & & & \\
SPANE-B & $-.480^{* *}$ & - & & & & \\
SWLS & $.530^{* * *}$ & $-.363^{* *}$ & - & & & \\
PHYS & $.278^{* *}$ & $-.294^{* *}$ & $.196^{*}$ & - & & \\
Family & $.249^{*}$ & -.154 & $.534^{* *}$ & .072 & - & - \\
Friends & $.349^{* *}$ & $-.245^{*}$ & $.248^{* *}$ & .043 & -.096 & - \\
\hline
\end{tabular}

*Indicates $p<.05$,

**Indicates $p<.001$

SWLS, and Flourishing measures, respectively. Specifically, in the first step, the area of residence (i.e., $0=$ urban, $1=$ Blue Zone) was inserted, in the second step the marital status was added, in the third step the perceived physical health measure was inserted, and finally, in the fourth step, the satisfaction with family and non-family relationships scores were added. It must be noticed that in the SPANE-B condition, in the fourth step we added only the satisfaction with friends score because the relationship between SPANE-B and satisfaction with family members was not statistically significant. Table 3 summarizes these outcomes.

Then, a series of Analyses of Covariance (ANCOVAs) was performed to explore the impact of socio-cultural context (i.e., Cagliari versus the Blue Zone) on eudaimonic (i.e., Flourishing) and hedonic (i.e., SPANE and SWLS indexes) well-being, physical health, satisfaction with family ties and satisfaction with non-family ties measures, while controlling for the effect of age. The main effect of socio-cultural context was found in Flourishing $[\mathrm{F}(198)=25.49$, $\left.p<0.0001, \eta p^{2}=0.21\right]$, SPANE $\left[\mathrm{F}(198)=6.13, p=0.02, \eta p^{2}=0.06\right]$, SWLS $[\mathrm{F}(198)=37.99$, $\left.p<0.0001, \eta \mathrm{p}^{2}=0.28\right]$, satisfaction with family ties $\left[\mathrm{F}(184)=5.41, p=0.02, \eta p^{2}=0.06\right]$ and satisfaction with non-family ties $\left[\mathrm{F}(184)=29.06, p<0.0001, \eta p^{2}=0.26\right]$ conditions, respectively. In contrast, the main effect of socio-cultural context was not significant in the physical health condition $[\mathrm{F}(198)=0.001, p=0.98]$. Similarly, there was not the significant main effect of age in any condition. Overall, participants from the Blue Zone reported better hedonic and eudaimonic well-being and better satisfaction with their social relationships than older participants living in the urban area. Table 4 illustrates these findings.

\section{Discussion and Conclusions}

The main aim of the current investigation was to examine whether the socio-cultural context (urban area versus Sardinian Blue Zone), perceived physical efficiency, and several socially-oriented factors (i.e., satisfaction with family and non-family ties, marital status) predicted some self-reported eudaimonic and hedonic well-being indexes in a sample of cognitively healthy community-dwelling older people. A further goal consisted in exploring whether the positive mental health patterns usually found in the older individuals living in the Sardinian Blue Zone (e.g., Fastame, Mulas and Pau, 2020), could be replicated using 


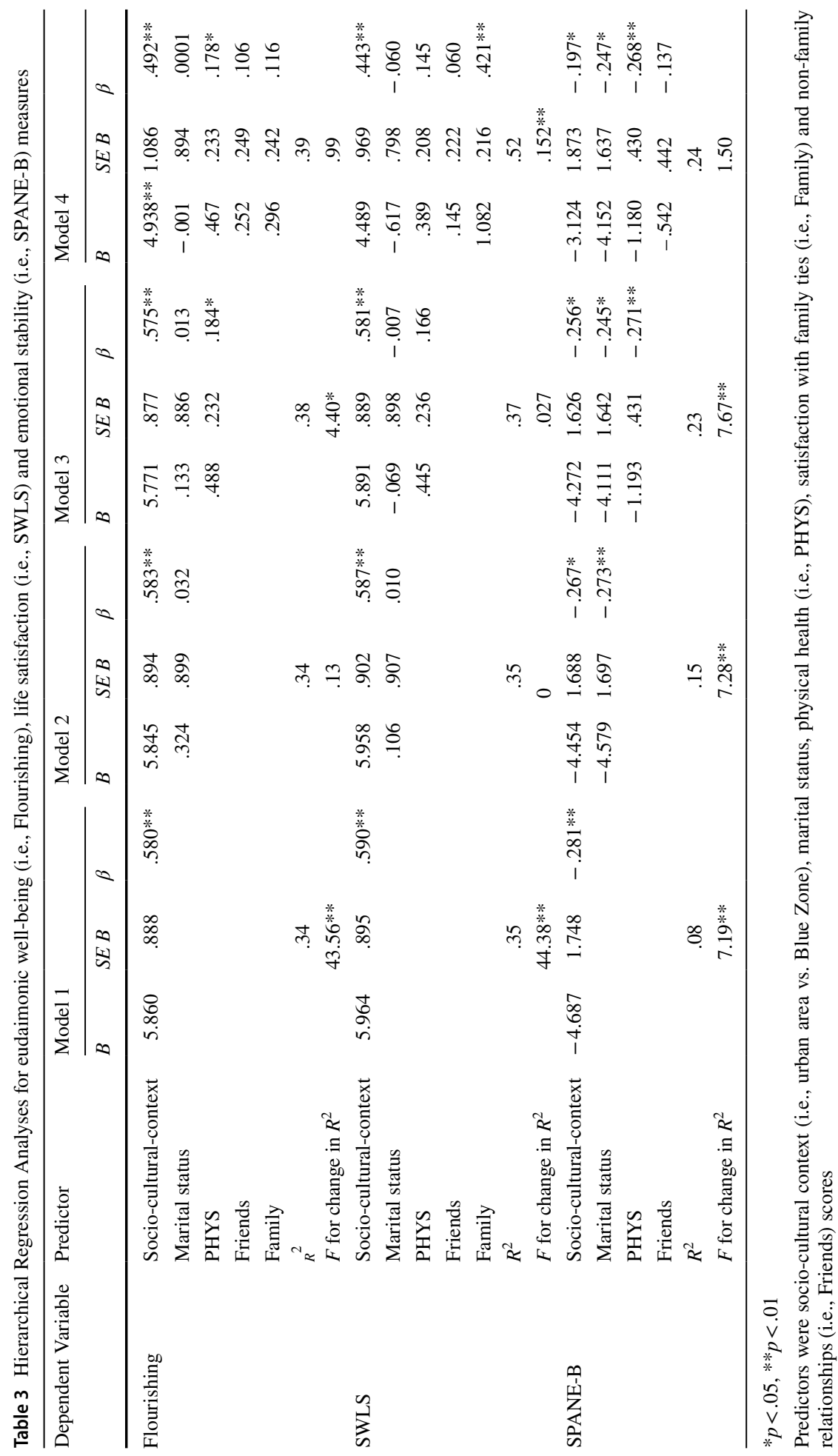


Table 4 Summary of ANCOVAs Analyses exploring the impact of socio-cultural context (urban vs Blue Zone areas) on self-reported eudaimonic (i.e., Flourishing) and hedonic (i.e., SPANE and SWLS) wellbeing, physical health (i.e., PHYS), satisfaction with family ties (i.e., Family satisfaction) and satisfaction with friendships (i.e., Friends satisfaction) measures, respectively

\begin{tabular}{llllllll}
\hline Dependent Variable & Main Effects & df & F & $p$ & $\eta^{2} p$ & $\begin{array}{l}\text { M urban } \\
\text { (Cagliari) }\end{array}$ & $\begin{array}{l}\text { M Blue Zone } \\
\text { (Dorgali) }\end{array}$ \\
\hline Flourishing & Socio-cultural context & 198 & 25.49 & $<.0001$ & .21 & $46.6(4.4)$ & $51.2(4.7)$ \\
& Age (covariate) & 198 & .24 & .62 & & & \\
SPANE-B & Socio-cultural context & 198 & 6.13 & .02 & .06 & $10.15(7.8)$ & $14.06(8.3)$ \\
& Age (covariate) & 198 & .26 & .61 & & & \\
SWLS & Socio-cultural context & 198 & 37.99 & $<.001$ & .28 & $27.73(5)$ & $32.83(2.7)$ \\
PHYS & Age (covariate) & 198 & 2.48 & .12 & & & \\
& Socio-cultural context & 198 & .001 & .98 & & $7.32(2.03)$ & $7.27(1.83)$ \\
Family Satisfaction & Age (covariate) & 198 & .98 & .32 & & & \\
& Socio-cultural context & 184 & 5.41 & .02 & .06 & $8.64(2.3)$ & $9.7(.96)$ \\
Friends Satisfaction & Age (covariate) & 184 & 1.76 & .18 & & & \\
& Socio-cultural context & 184 & 29.06 & $<.0001$ & .26 & $7.7(2.2)$ & $9.8(.7)$ \\
& Age (covariate) & 184 & 2.48 & .12 & & & \\
\hline
\end{tabular}

Age was used as a covariate. Mean scores distinguished for socio-cultural context have been also reported. Standard deviations are provided in parentheses

the aforementioned questionnaires and differentiated from the mental health pattern of the older people living in the urban area of Cagliari.

Overall, the outcomes of this study support the hypothesis that socio-cultural context is a highly significant factor predicting self-reported hedonic and eudaimonic well-being. Indeed, results of the regression analyses demonstrate that $8-35 \%$ of the variance relative to the well-being measures proposed to our participants was predicted by the context (i.e., Blue Zone versus Cagliari) in which the participants lived. Furthermore, apart from perceived physical functioning (which could reflect personal feelings of autonomy in daily life), further socially-oriented factors such as marital status and satisfaction with family ties were significant predictors of some facets of hedonic or eudaimonic well-being. Overall, these outcomes are consistent with previous findings (e.g., Diener et al., 2018; Fastame, 2020) which highlighted the crucial role played by social relationships in boosting perceived mental health in late adulthood. Moreover, these findings are also consistent with those found by Fastame, Mulas and Pau (2020), according to which a limited loss of motor efficiency over a period of two years concurred with the maintenance of greater psychological well-being and fewer signs of negative mood in successful older individuals living in the Sardinian Blue Zone. Additionally, in line with a recent cross-sectional study conducted throughout the world by Jebb et al. (2020), the current results show that marital status significantly predicted approximately $7 \%$ of the variance relative to the hedonic wellbeing score (i.e., SPANE-B). That is, people who were married reported higher positive affect than those who were single/widowed. Nonetheless, unlike previous studies (e.g., Fastame, Hitchcott, Mulas et al. 2018; Rojo-Perez et al., 2012), satisfaction with non-family relationships did not predict any measure of eudaimonic or hedonic well-being. Altogether, the current results confirm that different factors can account for distinct facets of wellbeing, pointing out the multidimensional nature of this construct. 
Moreover, the present findings corroborate and extend those reported in previous studies (e.g., Fastame, Penna and Rossetti, 2014; Fastame, Hichcott and Penna, 2015), showing that older inhabitants of the Sardinian Blue Zone reported better eudaimonic (e.g., personal growth, meaning construction) and hedonic (i.e., emotional regulation and life satisfaction) motives of individual well-being, and moreover expressed greater satisfaction with their social capital than individuals residing in the city of Cagliari. Indeed, respondents recruited in the Blue Zone reported very high levels of satisfaction with life and satisfaction with family and non-family ties, and reported more positively-oriented emotional regulation and a higher level of flourishing than the participants from the urban area. Thus, following some previous studies (e.g., Fastame, Penna and Rossetti, 2014; Fastame, Penna and Hitchcott, 2020; Heatherington 1999), the current findings suggest that, in a socio-cultural context such as that of the Sardinian Blue Zone, where a very simple lifestyle prevails and in which older people are encouraged to play an active role in their community (i.e., older adults as a depository of local traditions, expertise, and local cultural values), social support (i.e., living with one's spouse, and satisfaction with relationships with family members, friends, and neighbors) is crucial to boosting psychological markers of positive aging. Thus, extending some recent evidence (Kushlev et al., 2020), the current findings let us conclude that social engagement represents a more relevant factor impacting mental health, since older people more satisfied with their social relationships were also higher in hedonic and eudaimonic well-being. Consistently, unlike previous evidence suggesting that extrinsic factors (e.g. finances) are proximal factors having a positive impact on optimal aging (Martin \& Martin, 2002), this study shows that even though the main health services and more favorable economic capital were detected in Cagliari, better levels of well-being were found among the inhabitants of the Sardinian Blue Zone.

Therefore, from an applied perspective, this investigation suggests that the implementation of specific interventions promoting the maintenance in late adulthood of a positive social status (e.g., being useful for others, feeling respected and supported by others) into one's community can favor more propitious mental health outcomes in the third and fourth ages.

Some limitations of the study should be discussed. First, considering the exploratory nature of this study, to our knowledge, this is the first investigation in which the impact of the socio-cultural context (i.e., urban vs. rural area) on the aforementioned measures of hedonic and eudaimonic well-being has been examined among older people living in an area of exceptional longevity (i.e., Blue Zone) and in Cagliari. Thus, these outcomes cannot be generalized to longevous people living in other Blue Zones. Moreover, the sample size, the paucity of variables examined as possible predictors of self-reported well-being facets, and the limited battery of tests used in the current investigation to assess well-being suggest caution in generalizing these findings. Additionally, following Carver and Buchanan (2016), this study does not allow us to establish the contribution of caring engagement (i.e., support given to significant others encompassing friends and relatives) and productive engagement (i.e., a set of activities that contributes to others, such as family members or a social network) to the well-being of our participants. Therefore, further investigations are necessary to establish whether the mental health profile of older people of the Sardinian Blue Zone can be extended to older people living in further Blue Zone areas located in Costa Rica, Japan, and Greece (Poulain et al., 2013). Second, further studies are necessary to examine the cultural dimension of well-being. This will allow us to clarify whether the current results can be generalized to older individuals living in other Italian regions or whether these outcomes define a specific mental health trait of older people living in the exceptional longevity area of Sardinia. Third, further investigations are necessary to 
explore the role of other factors (e.g., cognitive reserve, leisure activities, religious coping) in predicting measures of hedonic and eudaimonic well-being in later life, and additional research is needed to clarify whether the current findings can be replicated using other measures of hedonic and eudaimonic well-being validated across cultures.

Author contribution The second and third authors recruited the participants, collected the data and were responsible for the scoring and the preparation of the input databases. The first author conceived the study, she was in charge of overall direction and planning and she took the lead in conducting the data analyses, writing and revising the manuscript. All authors discussed the results and commented on the manuscript. The final version of the manuscript was approved by the authors.

Funding Open access funding provided by Università degli Studi di Cagliari within the CRUI-CARE Agreement. This research did not receive any specific Grant from funding agencies in the public, commercial, or not-for-profit sectors.

Availability of data The data that support the findings of this study are not publicly available due to privacy or ethical restrictions.

\section{Declarations}

Conflict of interest The authors declare that they have no conflict of interest exists.

Ethics statement The study was conducted in accordance with the ethical standards of the institutional research committee and with the 1964 Helsinki Declaration and its later amendments. Written informed consent was given by all participants prior to participation.

Informed consent Participants provided written informed consent prior to take part in the study.

Open Access This article is licensed under a Creative Commons Attribution 4.0 International License, which permits use, sharing, adaptation, distribution and reproduction in any medium or format, as long as you give appropriate credit to the original author(s) and the source, provide a link to the Creative Commons licence, and indicate if changes were made. The images or other third party material in this article are included in the article's Creative Commons licence, unless indicated otherwise in a credit line to the material. If material is not included in the article's Creative Commons licence and your intended use is not permitted by statutory regulation or exceeds the permitted use, you will need to obtain permission directly from the copyright holder. To view a copy of this licence, visit http://creativecommons.org/licenses/by/4.0/.

\section{References}

Bowling, A. (1993). The concepts of successful and positive aging. Family Practice, 10, 449-453. https:// doi.org/10.1093/fampra/10.4.449

Carver, L. F., \& Buchanan, D. (2016). Successful aging: considering non-biomedical constructs. Clinical Interventions in Aging, 11, 1623-1630. https://doi.org/10.2147/CIA.S117202

Chyi, H., \& Mao, S. (2012). The determinants of happiness of China's elderly population. Journal of Happiness Studies, 13, 167-185. https://doi.org/10.1007/s10902-011-9256-8

Cohen, J. W. (1988). Statistical power analysis for the behavioral sciences (2nd edition). Lawrence Erlbaum Associates.

Cosco, T. D., Prina, A. M., Perales, J., Stephan, B. C., \& Brayne, C. (2014). Operational definitions of successful aging: a systematic review. International Psychogeriatrics, 26, 373-381. https://doi.org/10. $1017 / \mathrm{S} 1041610213002287$

Di Fabio, A., \& Gori, A. (2020). Satisfaction with life scale among italian workers: reliability, factor structure and validity through a big sample study. Sustainability, 12(14), 5860. https://doi.org/10.3390/ su12145860 
Diener, E., Emmons, R. A., Larsen, R. J., \& Griffin, S. (1985). The satisfaction with life scale. Journal of Personality Assessment, 49, 71-75. https://doi.org/10.1207/s15327752jpa4901_13

Diener, E., Seligman, M. E., Choi, H., \& Oishi, S. (2018). Happiest people revisited. Perspectives on Psychological Science, 13, 176-184. https://doi.org/10.1177/1745691617697077

Diener, E. D., Wirtz, D., Biswas-Diener, R., Tov, W., Kim-Prieto, C., Choi, D. W., \& Oishi, S. (2009). In E. Diener (Ed.), Assessing well-being: The collected works of Ed Diener (pp. 247-266). Russell Sage Foundation

Diener, E., Wirtz, D., Tov, W., Kim-Prieto, C., Choi, D., Oishi, S., \& Biswas-Diener, R. (2010). New wellbeing measures: short scales to assess flourishing and positive and negative feelings. Social Indicators Research, 97, 143-156. https://doi.org/10.1007/s11205-009-9493-y

Fastame, M. C. (2020). Life satisfaction in late adult span: the contribution of family relationships, health self-perception and physical activity. Aging Clinical and Experimental Research. https://doi.org/10. 1007/s40520-020-01658-1

Fastame, M. C., Hitchcott, P. K., Mulas, I., Ruiu, M., \& Penna, M. P. (2018). Resilience in elders of the sardinian blue zone: an explorative study. Behavioral Sciences, 8, 30. https://doi.org/10.3390/bs8030030

Fastame, M. C., Hitchcott, P. K., \& Penna, M. P. (2015). Do self-referent metacognition and residential context predict depressive symptoms across late-life span? a developmental study in an Italian sample. Aging and Mental Health, 19, 698-704. https://doi.org/10.1080/13607863.2014.962003

Fastame, M. C., Hitchcott, P. K., \& Penna, M. P. (2017). Does social desirability influence psychological well-being: perceived physical health and religiosity of Italian elders? a developmental approach. Aging \& Mental Health, 21, 348-353. https://doi.org/10.1080/13607863.2015.1074162

Fastame, M. C., Hitchcott, P. K., \& Penna, M. P. (2018). The impact of leisure on mental health of sardinian elderly from the 'blue zone': evidence for ageing well. Aging Clinical and Experimental Research, 30, 169-180. https://doi.org/10.1007/s40520-017-0768-x

Fastame, M. C., Mulas, I., \& Pau, M. (2020). Mental health and motor efficiency of older adults living in the sardinia's blue zone: a follow-up study. International Psychogeriatrics. https://doi.org/10.1017/S1041 610220001659

Fastame, M. C., \& Penna, M. P. (2014). Psychological well-being and metacognition in the fourth age: an explorative study in an italian oldest old sample. Aging and Mental Health, 18, 648-652. https://doi. org/10.1080/13607863.2013.866635

Fastame, M. C., Penna, M. P., \& Hitchcott, P. K. (2015). Mental health in late adulthood: what can preserve it? Applied Research in Quality of Life, 24, 241-244. https://doi.org/10.1007/s11482-014-9323-5

Fastame, M. C., Penna, M. P., \& Hitchcott, P. K. (2020). Psychological markers of longevity in sardinian centenarians: the impact of developmental factors and social desirability. Aging Clinical and Experimental Research, 31, 107-114. https://doi.org/10.1007/s40520-019-01157-y

Fastame, M. C., Penna, M. P., \& Rossetti, E. S. (2014). Perceived cognitive efficiency and subjective wellbeing in late adulthood: the impact of developmental factors. Journal of Adult Development, 21, 173180. https://doi.org/10.1007/s10804-014-9189

Fastame, M. C., Penna, M. P., Rossetti, E. S., \& Agus, M. (2014). The Effect of age and socio-cultural factors on self-rated well-being and metacognitive and mnestic efficiency among healthy elderly people. Applied Research Quality Life, 9, 325-334. https://doi.org/10.1007/s11482-013-9238-6

Fernandez-Ballesteros, R. (2011). Positive ageing: objective, subjective, and combined outcomes. Electronic Journal of Applied Psychology, 7, 22-30.

Folstein, M. F., Folstein, S. E., \& McHugh, P. R. (1975). Mini-mental state. a practical method for grading the cognitive state of patients for the clinician. Journal of Psychiatric Research, 12, 189-198. https:// doi.org/10.1016/0022-3956(75)90026-6

Giuntoli, L., Ceccarini, F., Sica, C., \& Caudek, C. (2017). Validation of the italian versions of the flourishing scale and of the scale of positive and negative experience. SAGE Open, 7, 1-12. https://doi.org/10. $1177 / 2158244016682293$

Gremigni, P., \& Stewart-Brown, S. L. (2011). Una misura del benessere mentale: validazione del warwickedinburgh mental well-being scale (WEMWBS) [measuring mental well-being: italian validation of the warwick-edinburgh mental well-being scale (WEMWBS)]. Giornale Italiano Di Psicologia, 2, 485-508.

Heatherington, T. (1999). Street tactics: catholic ritual and the senses of the past in central sardinia. Ethnology, 38, 315-334.

Hitchcott, P. K., Fastame, M. C., Ferrai, J., \& Penna, M. P. (2017). Psychological well-being in italian families: an exploratory approach to the study of mental health across the adult life span in the blue zone. Europe's Journal of Psychology, 13, 441-454. https://doi.org/10.5964/ejop.v13i3.1416 
Hitchcott, P. K., Fastame, M. C., \& Penna, M. P. (2018). More to blue zones than long life: positive psychological characteristics. Health, Risk \& Society, 20, 163-181. https://doi.org/10.1080/13698575.2018. 1496233.

Huta, V., \& Ryan, R. M. (2010). Pursuing pleasure or virtue: the differential and overlapping well-being benefits of hedonic and eudaimonic motives. Journal of Happiness Studies, 11, 735-762. https://doi. org/10.1007/s10902-009-9171-4

Jebb, A. T., Morrison, M., Tay, L., \& Diener, E. (2020). Subjective well-being around the world: trends and predictors across the life span. Psychological Science, 31, 293-305. https://doi.org/10.1177/09567 97619898826

Killen, A., \& Macaskill, A. (2015). Using a gratitude intervention to enhance well-being in older adults. Journal of Happiness Studies, 16, 947-964. https://doi.org/10.1007/s10902-014-9542-3

Kushlev, K., Drummond, D. M., Heintzelman, S. J., \& Diener, E. (2020). Do happy people care about society's problems? Journal of Positive Psychology, 15, 467-477. https://doi.org/10.1080/17439760.2019. 1639797

Lee, S. H., Lee, H., Kim, Y. S., Park, H. K., Lee, M. K., \& Kim, K. U. (2020). Social support is a strong determinant of life satisfaction among older adults with chronic obstructive pulmonary disease. The Clinical Respiratory Journal, 14, 85-91. https://doi.org/10.1111/crj.13104

Magni, E., Binetti, G., Bianchetti, A., Rozzini, R., \& Trabucchi, M. (1996). Mini-mental state examination: a normative study in italian elderly population. European Journal of Neurology, 3, 198-202. https:// doi.org/10.1111/j.1468-1331.1996.tb00423.x

Manca, C., Carta, G., Murru, E., Abolghasemi, A., Ansar, H., Errigo, A., \& Pes, G. M. (2021). Circulating fatty acids and endocannabinoidome-related mediator profiles associated to human longevity. GeroScience. https://doi.org/10.1007/s11357-021-00342-0

Martin, P., \& Martin, M. (2002). Proximal and distal influences on development: The model of developmental adaptation. Developmental Review, 22, 78-96. https://doi.org/10.1006/drev.2001.0538

Nieddu, A., Vindas, L., Errigo, A., Vindas, J., Pes, G. M., \& Dore, M. P. (2020). Dietary habits, anthropometric features and daily performance in two independent long-lived populations from nicoya peninsula (costa rica) and ogliastra (sardinia). Nutrients, 12(6), 1621. https://doi.org/10.3390/nu12061621

Nunnally, J. C., \& Bernstein, I. H. (1994). Psychological theory (3rd ed.). McGraw-Hill.

Pallant, G. (2016). SPSS Survival Manual (6 ${ }^{\text {th }}$ edition). Allen \& Unwin.

Pavot, W., \& Diener, E. (1993). Review of the satisfaction with life scale. Psychological Assessment, 5, 164-172. https://doi.org/10.1080/17439760701756946

Pes, G. M., Tolu, F., Dore, M. P., Sechi, G. P., Errigo, A., Canelada, A., \& Poulain, M. (2015). Male longevity in sardinia, a review of historical sources supporting a causal link with dietary factors. European Journal of Clinical Nutrition, 69, 411-418. https://doi.org/10.1038/ejen.2014.230

Pes, G. M., Tolu, F., Poulain, M., Errigo, A., Masala, S., Pietrobelli, A., \& Maioli, M. (2013). Lifestyle and nutrition related to male longevity in sardinia: an ecological study. Nutrition, Metabolism and Cardiovascular Diseases, 23(3), 212-219. https://doi.org/10.1016/j.numecd.2011.05.004

Poulain, M., Herm, A., \& Pes, G. M. (2013). The blue zones: areas of exceptional longevity around the world. Vienna Yearbook of Population Research, 11, 87-108.

Radloff, L. S. (1977). The CES-D scale: a self-report depression scale for research in the general population. Applied Psychological Measurement, 1, 385-401. https://doi.org/10.1177/014662167700100306

Rojo-Perez, F., Fernandez-Mayoralas, G., Rodriguez-Rodriguez, V., Forjaz, M. J., Rodriguez-Blazquez, C., Prieto-Flores, M. E., \& Martinez-Martin, P. (2012). The personal wellbeing among community-dwelling older adults in spain and associated factors. Journal of Social Research \& Policy, 3(2), 67-94.

Tennant, R., Hiller, L., Fishwick, R., Platt, S., Joseph, S., Weich, S., \& Stewart-Brown, S. (2007). The warwick-edinburgh mental well-being scale (WEMWBS): development and UK validation. Health and Quality of Life Outcomes., 5, 63. https://doi.org/10.1186/1477-7525-5-63

VandenBos, G. R., \& American Psychological Association (2015). APA Dictionary of Psychology $\left(2^{\text {nd }}\right.$ edition). American Psychological Association.

Williams, L., Zhang, R., \& Packard, K. C. (2017). Factors affecting the physical and mental health of older adults in China: The importance of marital status, child proximity, and gender. SSM - Population Health, 3, 20-36. https://doi.org/10.1016/j.ssmph.2016.11.005

Publisher's Note Springer Nature remains neutral with regard to jurisdictional claims in published maps and institutional affiliations. 